\title{
Correction to: Transperineal minimally invasive abdominoperineal resection for low rectal cancer: standardized technique and clinical outcomes
}

Takeru Matsuda $^{2}\left(\right.$ Kimihiro Yamashita $^{1} \cdot$ Hiroshi Hasegawa $^{1} \cdot$ Gosuke Takiguchi $^{1} \cdot$ Naoki Urakawa $^{1}$. Masashi Yamamoto ${ }^{1}$. Shingo Kanaji ${ }^{1} \cdot$ Taro Oshikiri $^{1} \cdot$ Tetsu Nakamura $^{1} \cdot$ Satoshi Suzuki ${ }^{1} \cdot$ Yoshihiro Kakeji $^{1}$

Published online: 2 September 2021

๑) The Author(s), under exclusive licence to Springer Science+Business Media, LLC, part of Springer Nature 2021

\section{Correction to: Surgical Endoscopy}

https://doi.org/10.1007/s00464-021-08633-5

This article was updated to correct the formatting of Table 3.

Publisher's Note Springer Nature remains neutral with regard to jurisdictional claims in published maps and institutional affiliations.

The original article can be found online at https://doi.org/10.1007/ s00464-021-08633-5.

Takeru Matsuda

takerumatsuda@nifty.com

1 Division of Gastrointestinal Surgery, Department of Surgery,

Kobe University Graduate School of Medicine, Kobe, Japan

2 Division of Minimally Invasive Surgery, Department of Surgery, Kobe University Graduate School of Medicine, 7-5-2 Kusunoki-chou, Chuo-ku, Kobe 650-0017, Japan 